\title{
EXPRESSION OF FRONTOTEMPORAL DEMENTIA WITH PARKINSONISM ASSOCIATED TO CHROMOSOME 17 TAU INDUCES SPECIFIC DEGENERATION OF THE VENTRAL DENTATE GYRUS AND DEPRESSIVE-LIKE BEHAVIOR IN MICE
}

\author{
M. LLORENS-MARTIN, ${ }^{a}$ F. HERNANDEZ ${ }^{\mathrm{a}, \mathrm{b}}$ AND \\ J. AVILA ${ }^{\mathrm{a}, \mathrm{b} *}$ \\ ${ }^{a}$ Centro de Biología Molecular Severo Ochoa (CSIC-UAM), C/Nicolás \\ Cabrera 1, Universidad Autónoma de Madrid, Campus Cantoblanco, \\ 28049 Madrid, Spain \\ ${ }^{b}$ Centro de Investigación Biomédica en Red sobre Enfermedades \\ Neurodegenerativas (CIBERNED), c/Valderebollo, 5, 28031 Madrid, \\ Spain
}

\begin{abstract}
When bearing certain frontotemporal dementia with parkinsonism (FTDP) mutations, overexpression of human tau resulted in a decrease of the dentate gyrus ventral blade, apparently due to a reduction in the proliferation of neuronal precursors and an increase in neuronal cell death. This degenerative process was accompanied by a dramatic increase in behavioral despair, as evident in the Porsolt swim test. Interestingly, we observed an increase in GABAergic innervation in the molecular layer of the dorsal dentate gyrus but not in the ventral domain. We suggest that this increase in GABAergic innervation reflects a compensatory neuroprotective response to the overexpression of toxic tau, which may prevent or delay degeneration in the dorsal blade of the dental gyrus. Finally, we suggest that this transgenic mouse, which overexpresses human FTPD tau, may serve as a useful model to study specific functions of the ventral dentate gyrus. () 2011 IBRO. Published by Elsevier Ltd. All rights reserved.
\end{abstract}

Key words: neurogenesis, depression, ventral dentate gyrus, frontotemporal dementia, tau, neurodegeneration.

Tau is a protein that binds and stabilizes assembled microtubules by suppressing microtubule dynamics (Panda et al., 1995). Although mice lacking tau are viable (Harada et al., 1994; Dawson et al., 2001), tau deficiency delays neurite extension in cultured neurons (Caceres and Kosik, 1990 ), and it leads to the upregulation of BAF-57, a protein involved in neuron-specific gene expression (Gómez de Barreda et al., 2010). Together these data suggest a role for tau in neuron maturation. In addition, alterations to tau involving increase in its expression (Andorfer et al., 2005), modification by phosphorylation (Alonso et al., 2010; de Barreda et al., 2010) or mutation (Hutton et al., 1998) can provoke neurodegeneration. Indeed, the identification of

*Corresponding author. Tel: +34-91-196-45-64; fax: +34-91-196-44-20. E-mail address: javila@cbm.uam.es (J. Avila).

Abbreviations: AHN, adult hippocampal neurogenesis; DCX, doublecortin; DG, dentate gyrus; FTPD-17, frontotemporal dementia with parkinsonism associated to chromosome 17; GAD65, glutamic acid decarboxylase 65; IdU, 5-lodo-2'-deoxyuridine; PH3, phosphor-histone 3 ; qPCR, quantitative polymerase chain reaction; wt, wild type. mutations in the tau gene as the cause of inherited frontotemporal dementia with parkinsonism associated to chromosome 17 (FTPD-17) demonstrate that tau modifications are sufficient to trigger neurodegeneration (Goedert and Spillantini, 2000).

To investigate how alterations to tau provoke neurodegeneration, we generated transgenic mice carrying three FTPD-17 missense mutations in tau: G272V, P301L, and $\mathrm{R} 408 \mathrm{~W}\left(\mathrm{Tg}\right.$ tau $\left.^{\mathrm{VLW}}\right)$. These mice demonstrate the toxic effect of mutated tau protein in this model (Lim et al., 2001), although no important morphological differences were observed between these tau ${ }^{\mathrm{VLW}}$ and wild type (wt) mice, either in Ammon's horn of the hippocampus or in the dorsal dentate gyrus (Engel et al., 2006). However, in the last study only dorsal regions were analyzed, and in rodents, significant structural and functional differences exist between the dorsal and ventral hippocampal areas (Fanselow and Dong, 2010), reflecting functional specialization. The dorsal dentate gyrus is primarily involved in memory and learning processes, whereas ventral areas are associated with anxiety and emotional processes (Snyder et al., 2009). A unique feature of the dentate gyrus is the persistence of adult hippocampal neurogenesis (AHN) throughout the lifespan of the animal, as demonstrated in numerous vertebrates, including humans (Knoth et al., 2010). There is increasing evidence that this process is crucial for learning and memory (Deng et al., 2010), and numerous external stimuli have been shown to modulate AHN, including physical activity (van Praag et al., 1999), environmental enrichment (Llorens-Martín et al., 2010), and stress. In addition, alterations in AHN have been implicated in several mood disorders (Samuels and Hen, 2010) and in the onset and development of neurodegenerative diseases (Winner et al., 2011).

In the present study, we investigated the putative pathogenic effects of human tau ${ }^{\vee L W}$ expression in the mouse ventral dentate gyrus. We observed an early neurodegenerative effect of this altered tau protein that was characterized by a specific decrease in neurogenesis in the ventral dentate gyrus. The implications of this impairment in neurogenesis are discussed.

\section{MATERIALS AND METHODS}

\section{Animals}

VLW transgenic mice have been generated (Lim et al., 2001) using a transgene to express the largest human CNS tau isoform containing the two $\mathrm{N}$-terminal inserts $(2 \mathrm{~N})$, four microtubule-bind- 
ing repeat elements (4R), and the three FTDP-17-linked mutations (see Fig. 1): G272V (V), P301L (L), and R406W (W). These mutations were incorporated by site-directed mutagenesis of the human tau cDNA. Neuron-specific expression was directed by inserting the cDNA into a murine thy 1 gene expression cassette between exons 2 and 4.

In these experiments, we used 20 female VLW mice (16-19 weeks old) and 20 C57/BL6J female control mice (16-19 weeks old), both from Harlan Laboratories. Animals were housed at $22 \pm 1^{\circ} \mathrm{C}$ on a $12 / 12 \mathrm{~h}$ light/dark cycle, and with ad libitum access to food and water. Mice were housed under standard laboratory conditions in accordance with European Community Guidelines (directive 86/609/EEC). All animals were handled in strict accordance with good animal practice as defined by the national animal welfare bodies (Universidad Autónoma de Madrid and CSIC, the Higher Scientific Research Council), and all animal work was approved by the Bioethics Committee at the Centro de Biología Molecular "Severo Ochoa."

\section{Experimental design and injection of the thymidine analogue}

Animals were given a single injection of 5-iodo-2'-deoxyuridine (IdU, $42.75 \mathrm{mg} / \mathrm{kg}$ bw. i.p.; Sigma-Aldrich) $24 \mathrm{~h}$ before they were sacrificed. This dose was chosen as it is an equimolar dose of 50 $\mathrm{mg} / \mathrm{kg} \mathrm{BrdU}$, as previously described (Llorens-Martín et al., 2010). The mice were fully anesthetized with pentobarbital $24 \mathrm{~h}$ after IdU injection and divided into two groups: for immunohistochemical (10 animals per genotype) and quantitative polymerase chain reaction (qPCR) analysis (four animals per genotype). For immunohistochemistry, the mice were perfused with saline followed by $4 \%$ paraformaldehyde in phosphate buffer (PB), after which their brain was removed and postfixed overnight in the same fixative. For qPCR analysis, mice were perfused with saline alone. In qPCR cases, the hippocampus of each animal was removed on ice, separated into dorsal and ventral regions, and frozen at $-80{ }^{\circ} \mathrm{C}$.

\section{Histology}

Sagittal vibratome sections (50 $\mu \mathrm{m}$ thick) from one hemisphere were obtained (Leica VT1000S), and series of sections were generated with every 8th section. Dual or triple immunohistochemistry was performed as described previously (Llorens-Martín et al., 2006) using the following primary antibodies: mouse anti-IdU (1: 500, BD Biosciences, NJ, USA); rabbit anti-phospho-histone 3 (PH3, 1:500, Upstate-Cell Signaling, Boston, MA, USA); goat anti-doublecortin (DCX, 1:500, Santa Cruz, CA, USA); rabbit antifractin (1:500, BD Biosciences); rabbit anti-calretinin (1:2000, Swant, Switzerland); mouse anti PHF-1 (1:1000, a kind gift from Dr. Peter Davis, NY, USA); and mouse anti-glutamic acid decarboxylase 65 (GAD65, 1:500, Developmental Hybridoma Bank, IA, USA). The binding of these antibodies over $24-48 \mathrm{~h}$ was detected by incubating for $24 \mathrm{~h}$ at $4{ }^{\circ} \mathrm{C}$ with the following donkey Alexaconjugated secondary antibodies (1:1000, Molecular Probes, Eugene, OR, USA) as appropriate: Alexa 555-conjugated anti-rabbit (PH3 and fractin); Alexa 633-conjugated anti-goat (doublecortin); Alexa 488-conjugated anti-rabbit (calretinin); Alexa 555-conjugated anti-mouse (GAD65), and Alexa 488-conjugated antimouse (IdU and PHF-1). All the sections were finally counterstained for $10 \mathrm{~min}$ with $4^{\prime}, 6$-diamidino-2-phenylindole (DAPI) (1: 1000, Calbiochem-EMD Darmstadt, Germany).

\section{Stereological cell counting and estimation of dentate gyrus volume}

Slices comprising the entire hippocampus of each mouse, from the $3.925 \mathrm{~mm}$ lateral position where the dentate gyrus is not yet present to the midline $(0.00 \mathrm{~mm}$ lateral position), were collected in a 96-well plate. In order to analyze the dorsal and ventral dentate gyrus separately, three different regions of the hemisphere were considered. The most lateral region was comprised of sagittal sections ranging from lateral position $3.325 \mathrm{~mm}$ to $2.725 \mathrm{~mm}$, contained single dentate gyrus profiles. In this region, the dentate gyrus was divided equally into the dorsal and ventral regions, and each was analyzed separately. The second region (located medial to the first) was comprised of sections ranging from lateral position $2.725 \mathrm{~mm}$ to $1.95 \mathrm{~mm}$. Dorsal and ventral regions of the dentate gyrus profiles appear separately in this region and they were therefore readily distinguished. The third and most medial part of the hemisphere was comprised of sections ranging from the lateral position $1.95 \mathrm{~mm}$ to the midline. As the ventral portion of the dentate gyrus is absent in these sections, only the dorsal region was analyzed. The volume of both the dorsal and ventral dentate gyrus was estimated stereologically by applying the Cavalieri method to each series of Nissl stained sections, as described previously (Llorens-Martín et al., 2006).

Under an optical fluorescence microscope (Zeiss Axiovert 200 , oil immersion, $40 \times$ objective), the total number of cells labeled for $\mathrm{PH} 3$, fractin, and IdU were counted using the opticaldissector method, as described previously (Llorens-Martín et al., 2006). Briefly, cells labeled for each marker were counted separately in the dorsal and ventral regions of each section in series made up of every 8 th section. The total number was divided by the corresponding dorsal or ventral volume of the dentate gyrus in the section to obtain a measure of cell density $\left(\right.$ cells $\left./ \mathrm{mm}^{3}\right)$. The average density for the entire series was then multiplied by the volume of the total dorsal or ventral dentate gyrus in order to determine the total number of cells.

The total number of immature $\left(\mathrm{DCX}^{+}\right)$and mature granule neurons was calculated using the physical-dissector method adapted for confocal microscopy (Zeiss LSM710), as described elsewhere (Llorens-Martín et al., 2006). The number of samples used was modified to analyze the dorsal and ventral regions of the dentate gyrus separately. Thus, four stacks of images obtained from each region (dorsal or ventral) were analyzed per animal.

The area occupied by GABAergic terminals was measured in the molecular layer of sections stained for GAD65 in confocal microscopy images (oil immersion, $63 \times$ objective, 2.3 Zoom: Zeiss LSM710).

To estimate the percentage of immature $\mathrm{DCX}^{+}$neurons that also expressed hyperphosphorylated tau protein (PHF-1), high magnification stacks of confocal images were used (oil immersion, $63 \times$ objective, 1.3 Zoom: Zeiss LSM710 microscope). The phenotype of a minimum of $50 \mathrm{DCX}^{+}$cells per animal was analyzed in the dorsal and ventral zones, and the data are presented as the percentage of the number of $\mathrm{DCX}^{+}$cells.

\section{Quantitative real-time polymerase chain reaction (qPCR)}

Total RNA was isolated from the hippocampal tissue of each mouse using the Illustra RNAspin Mini kit (GE Healthcare, Uppsala, Sweden), and it was reverse transcribed $(1 \mu \mathrm{g})$ using the High capacity cDNA Reverse Transcription kit (Applied Biosystems, Carlsbad, CA, USA). Subsequently, qPCR was carried out on an ABI PRISM 7900HT SDS thermal cycler (Applied Biosystems), and the data were analyzed using GenEx software (Freising-Weihenstephan, Germany). The primers used were designed to target the murine tau gene, and detection of the human tau was avoided by targeting a region not present in the human tauVLW transgene. Thus, the pair of primers spanning an intron that used to detect and amplify the human tau gene were: (sense, $5=-$ GCAGGCATTGGAGACACC-3= and antisense, 5=-TTTACTGACCATGCGAGCTT21-3'), whereas those used to detect and amplify the murine tau gene were (sense, $5^{\prime}$-ACCACAGCCACCTTCTCCT-3' and antisense, 5'- CAGCCATCCTGGTTCAAAGT-3'). All samples were run in triplicate on 384-well plates, 
A $--1-1 \cdot 2 \cdot 3 \cdot 4 \cdot 4 a-5 \cdot-6 \cdot 7 \cdot 8 \cdot 9 \cdot 10-11,12 \cdot 13,14-$ tau mRNAs

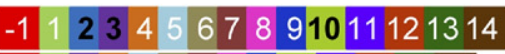

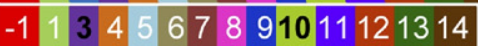
$-1114567891011121314$ $\begin{array}{llllllllll}-1 & 1 & 2 & 3 & 4 & 5 & 6 & 7 & 8 & 911121314\end{array}$ $\begin{array}{lllllllll}-1 & 1 & 3 & 4 & 5 & 6 & 7 & 8 & 911121314\end{array}$

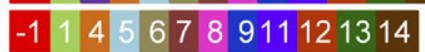

Tau Isoforms
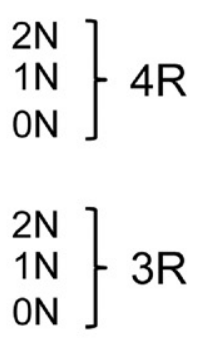

B

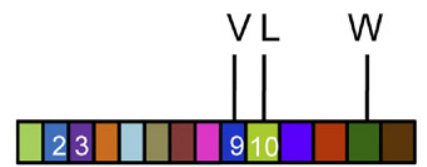

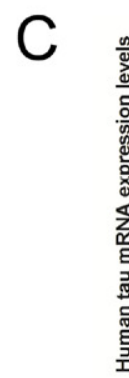

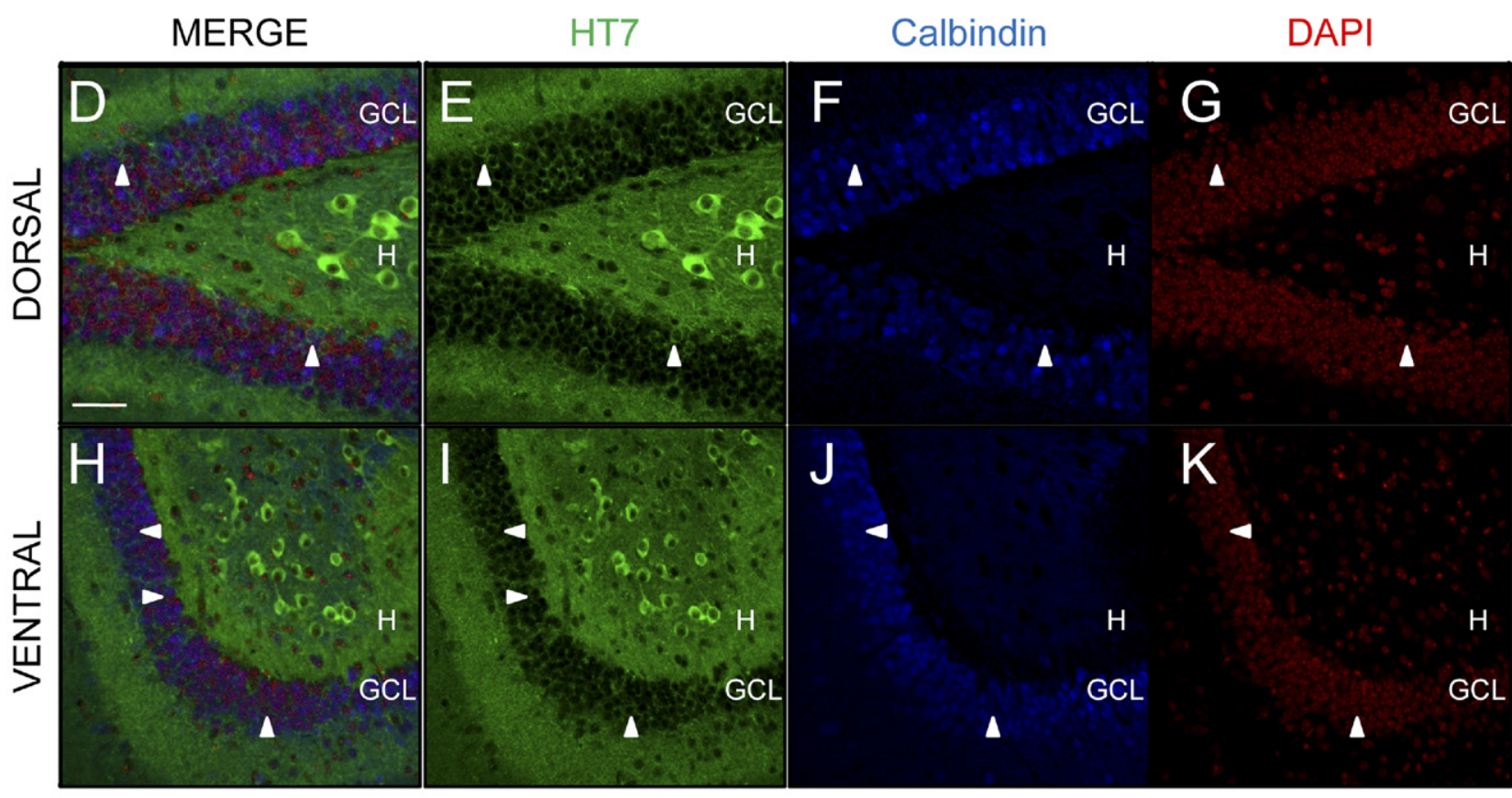

$\mathrm{L}$

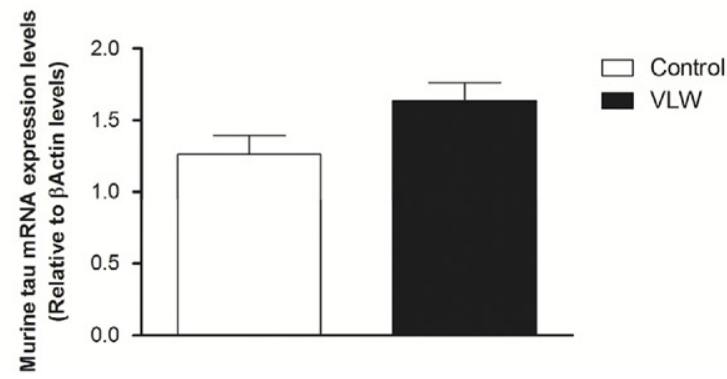

$\mathrm{M}$

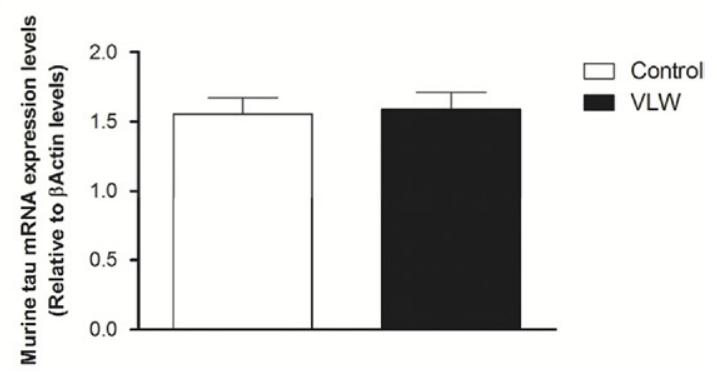

Fig. 1. Human and endogenous murine tau expression in tau ${ }^{\mathrm{LW}}$ transgenic mice and control animals. (A) The different tau cDNA isoforms expressed in the CNS. It should be noted that Tau4R isoforms contain four imperfect repetitions of the microtubule-binding domain, whereas Tau3R isoforms contain only three imperfect repetitions. (B) Diagram showing the tau ${ }^{\mathrm{LW}}$ transgene that contains four repetitions of the microtubule-binding domain and three FTPD-17 missense mutations: G272V, P301L, and R408W ( $\mathrm{Tg}$ tau ${ }^{\mathrm{VLW}}$ ). (C) Human tau mRNA expression in the dorsal and ventral dentate gyrus (DG) of the Tau ${ }^{\vee L W}$ mice as measured by quantitative polymerase chain reaction (qPCR, relative to $\beta$-Actin). (D-K) Human Tau protein in the dorsal $(D-G)$ and ventral $(H-K)$ DG detected with the HT7 anti-Tau antibody, which specifically recognizes human but not murine Tau. As shown in the images, human Tau is expressed equally by hippocampal neurons in the dorsal and ventral domains. Green: HT7 (human Tau); Blue: Calbindin; Red: DAPI. H, hilus. GCL, granule cell layer. White arrowheads indicate human tau-expressing neurons. Scale bar: $50 \mu \mathrm{m}$. (L, M) Murine tau mRNA expression in the dorsal and ventral DG of control and Tau ${ }^{\mathrm{VLW}}$ mice measured by qPCR (relative to $\beta$-Actin). Endogenous murine tau expression is not altered in the dorsal $(L)$ or ventral DG $(M)$ in tau ${ }^{V L W}$ transgenic mice when compared with control animals. For interpretation of the references to color in this figure legend, the reader is referred to the Web version of this article. 
and a melting curve for each amplification product was generated in order to assess the specificity of the amplification products after the last cycle of amplification. In all cases, $\beta$-actin was analyzed as a housekeeping gene for normalization, and efficiency curves (composed by six dilution points) were generated for each pair of primers. The following thermal amplification protocol was used with the Fast EvaGreen mastermix (Fisher Molecular Biology, Trevose, USA): $30^{\prime \prime}$ at $95^{\circ} \mathrm{C} ; 5^{\prime \prime}$ at $95^{\circ} \mathrm{C}+5^{\prime \prime}$ at $60^{\circ} \mathrm{C}, 40$ cycles; and $5^{\prime \prime}$ at $60{ }^{\circ} \mathrm{C}+5^{\prime \prime}$ at $95^{\circ} \mathrm{C}$. Mean $\mathrm{C}_{\mathrm{t}}$ was calculated for each sample and normalized to the mean $\mathrm{C}_{t}$ of the housekeeping gene, using a comparative $C_{t}\left(2^{-\delta \delta C t}\right)$ relative quantification method, as described previously (Wong and Medrano, 2005).

\section{Porsolt test}

On two consecutive days, six animals of each genotype were placed for $6 \mathrm{~min}$ in a cylinder $(12 \mathrm{~cm}$ diameter, $29 \mathrm{~cm}$ tall) filled with water at $23^{\circ} \mathrm{C}$. The animal's behavior was recorded on video on the second day, and the resulting video transferred directly to hard disk. Three different categories of animal behaviors were considered, climbing, swimming, and immobility, as described by Detke et al. (1995). Climbing was defined as a repetitive movement of the limbs, with forelimbs striking the cylinder walls, both hind limbs swinging in the water and the spine of the mouse in a vertical position. Swimming was defined as treading of the water with the hind limbs resulting in a clear displacement of the body for at least one lap of the cylinder, with the spine in a horizontal position. In addition, a fourth category termed "floating" was introduced. Floating was defined as movements clearly performed to maintain the head above water. Finally, immobility was considered the remaining time. When assessing the results of the test, the first minute of each video was discarded (as described previously Porsolt et al., 1977; Petit-Demouliere et al., 2005), and the data were presented as the time of immobility plus floating on the second day.

\section{Statistical analysis}

The data were analyzed by one-way ANOVA to compare experimental groups. A nonparametric test ( $U$ Mann-Whitney test) was used to analyze the qPCR data. SPSS 17.0.1 software (SPSS, 1989; Apache Software Foundation) was used for all statistical analyses.

\section{RESULTS}

\section{Equivalent levels of human or murine tau in dorsal and ventral regions of the DG in tau ${ }^{\mathrm{VLW}}$ mice}

Six different tau isoforms exist in the CNS (Fig. 1A) and in adult mice, tau isoforms containing $4 \mathrm{R}$ predominate (Avila et al., 2004). In addition to the mouse tau isoforms, the transgenic mouse studied here also expressed the longest human CNS tau isoform (containing the two $\mathrm{N}$-terminal insets, derived from exons 2 and 3 , and exon 10). Moreover, this human tau isoform contained three mutations (G272V, P301L, and R406W: Fig. 1B) that have been identified in human patients with temporal dementia linked to chromosome 17 (FTDP-17). Neuronal expression of this human tau isoform was directed by cloning the cDNA into a mouse thy 1 promoter cassette (Lim et al., 2001).

We analyzed the mRNA and protein expression of the human tau ${ }^{\mathrm{VLW}}$ isoform in the mouse dentate gyrus, where AHN occurs, detecting this protein isoform with the HT7 antibody that specifically recognizes human tau (Fig. 1B). Tau ${ }^{\mathrm{VLW}}$ was expressed similarly in both dorsal and ventral regions of the dentate gyrus (DG) and indeed, similar levels of human tau mRNA were observed in both DG regions by qPCR $(P=0.827$ : Fig. $1 \mathrm{C})$. Moreover, the majority of mature calbindin-expressing granule neurons in the dentate gyrus also expressed human tau (Fig. 1D-K). Finally, the expression of murine tau mRNA was also quantified by qPCR, and no differences in murine tau expression were found between control and transgenic tau ${ }^{\mathrm{VLW}}$ animals in either the dorsal $(P=0.1$, Fig. $1 \mathrm{~L})$ or ventral regions of the dentate gyrus $(P=0.7$ : Fig. $1 \mathrm{M})$.

\section{The volume of the ventral DG and cell number decrease specifically in tau ${ }^{\mathrm{VLW}}$ mice}

We assessed the consequences of expressing the mutated human tau in the dorsal and ventral regions of the DG in 4-month-old transgenic mice. In these animals, there was a decrease in the volume of the ventral DG when compared with their wild type counterparts $\left(F_{1,19}=8.007\right.$, $P=0.011$ : Fig. $2 A-D)$, whereas no differences in the volume of the dorsal DG were observed $\left(F_{1,19}=0.427\right.$, $P=0.522$ : Fig. $2 \mathrm{~A}-\mathrm{C})$. The decrease in the volume of the ventral region of the $D G$ observed in transgenic mice may reflect a parallel decrease in the number of mature granule cells in this region $\left(F_{1,19}=10.466, P=0.005\right.$ : Fig. $\left.2 \mathrm{G}, \mathrm{H}, \mathrm{J}\right)$. Indeed, there were fewer granule cells present in the ventral DG of transgenic mice when compared with the wild type mice (Fig. 2J), whereas no significant differences in granule cell number were evident in the dorsal blade of the dentate gyrus $\left(F_{1,19}=0.002 ; P=0.962\right.$ : Fig. $2 \mathrm{E}, \mathrm{F}$ and quantified in Fig. 2l).

\section{Decreased cell proliferation may account for the reduction in ventral DG volume in tau ${ }^{\mathrm{VLW}}$ mice}

Since the dentate gyrus is one of the few brain regions where AHN occurs, the total number of neurons in this region at a specific age reflects the ratio of the dead to newborn neurons. Since the number of newborn neurons is related to the proliferation of neuronal precursors, we assessed the number of proliferating (mitotic) cells in the dorsal and ventral regions of the DG by counting the number of phosphohistone $\mathrm{H} 3$ (a mitotic marker) positive cells ( $\mathrm{PH} 3$ cells) in each area. In the ventral $D G$ of tau ${ }^{\vee L W}$ mice, there was a decrease in the number of $\mathrm{PH}^{+}$cells with respect to the wt mice $\left(F_{1,18}=4.840, P=0.042\right.$ : Fig. $\left.3 \mathrm{E}, \mathrm{F}, \mathrm{H}\right)$. By contrast, there was no difference in the proliferation of neuronal precursors in the dorsal DG between mutant and wt mice $\left(F_{1,19}=0.024, P=0.879\right.$ : Fig. $\left.3 A-D, G\right)$.

As the number of neurons in the DG is also affected by neuronal death, a function of cell survival, we analyzed cell survival in the DG after quantifying the number of surviving cells that were labeled by IdU injection $24 \mathrm{~h}$ prior to sacrifice. Fewer IdU labeled cells were observed in the ventral DG of transgenic tau ${ }^{\mathrm{VLW}}$ when compared with wt mice $\left(F_{1,15}=8.650 ; P=0.011\right.$ : Fig. $\left.3 G-L\right)$, although there were no differences observed in the dorsal region $(P=0.053)$. In order to assess specific neuro- 

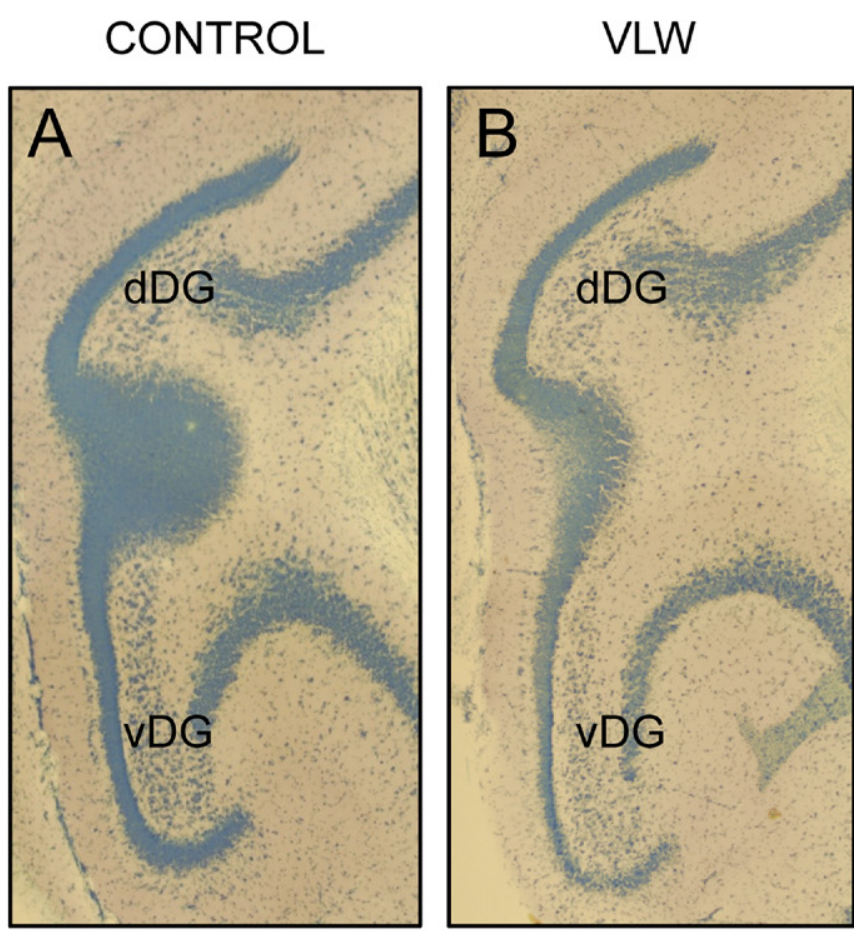

\section{C}

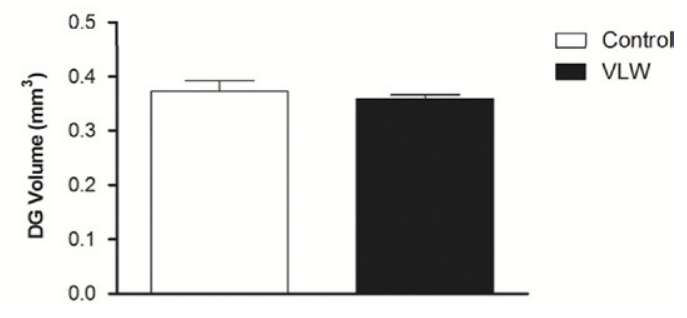

$\mathrm{D}$

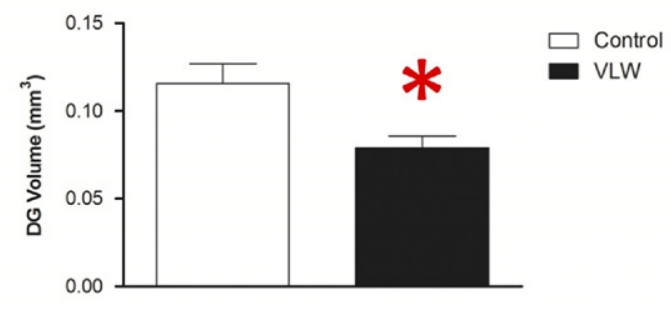

\section{CONTROL}
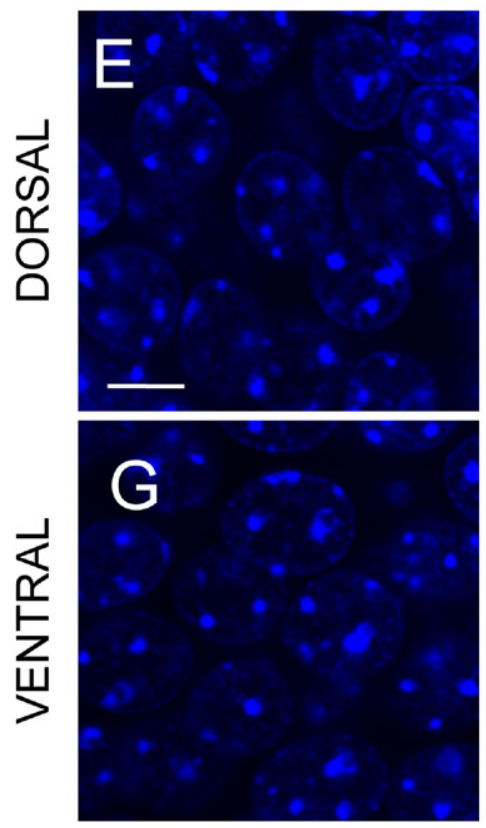

VLW
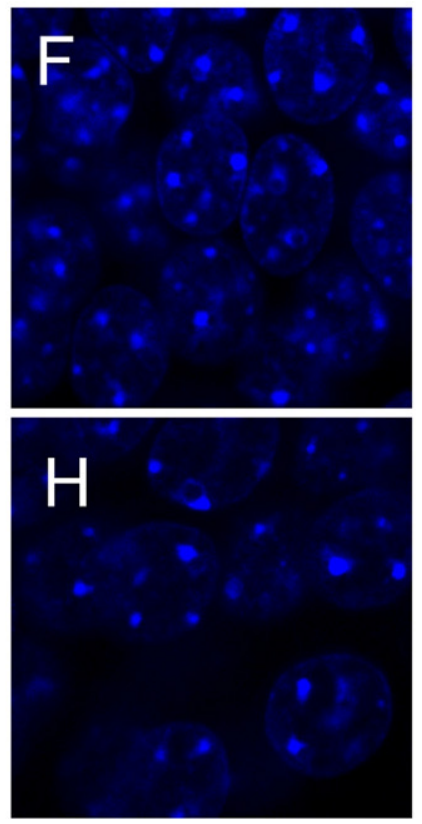

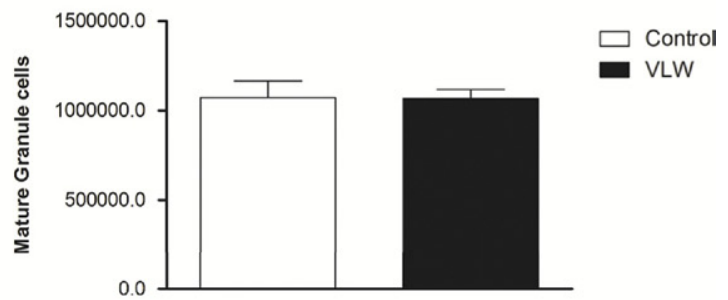

$J$

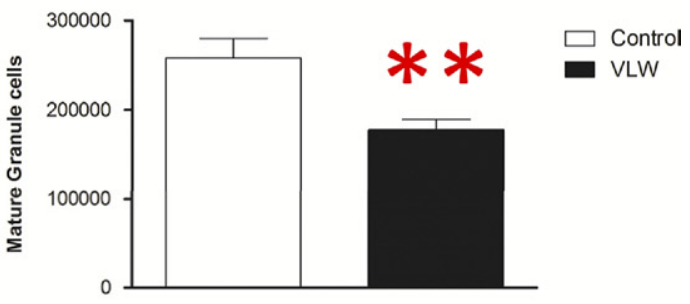

Fig. 2. Alterations to the ventral dentate gyrus (DG) of tau ${ }^{\mathrm{VLW}}$ mice. (A, B) Representative images of a Nissl-stained dentate gyrus from a control (A) and transgenic tau ${ }^{\mathrm{VLW}}$ mouse (B). The images show the decrease in ventral dentate gyrus volume in tau ${ }^{\mathrm{VLW}}$ mice. (C, D) Quantification of dorsal (C) and ventral (D) DG volume. (E-H) Representative high magnification images of the granule cell layer of control (E, G) and transgenic tau ${ }^{\mathrm{VLW}}$ mice $(\mathrm{F}$, H) stained with DAPI. (I, J) Quantification of the number of mature granule neurons in the dorsal (I) and ventral (J) DG demonstrating that there are significantly fewer mature granule neurons in the ventral DG of tau ${ }^{\mathrm{VLW}}$ mice. Scale bar: $10 \mu \mathrm{m}$. For interpretation of the references to color in this figure legend, the reader is referred to the Web version of this article. ${ }^{*} 0.05>P>0.01 ;{ }^{*} 0.01>P>0.001$.

blasts's early survival, we quantified the percentage of IdU ${ }^{+}$cells that also expressed DCX, and found no significant differences between tau ${ }^{\mathrm{VLW}}$ and wt mice (data not shown). Given that the differences in early survival observed were similar to those seen for $\mathrm{PH}^{+}$cells, the alteration in neuronal number would appear to be pri- 

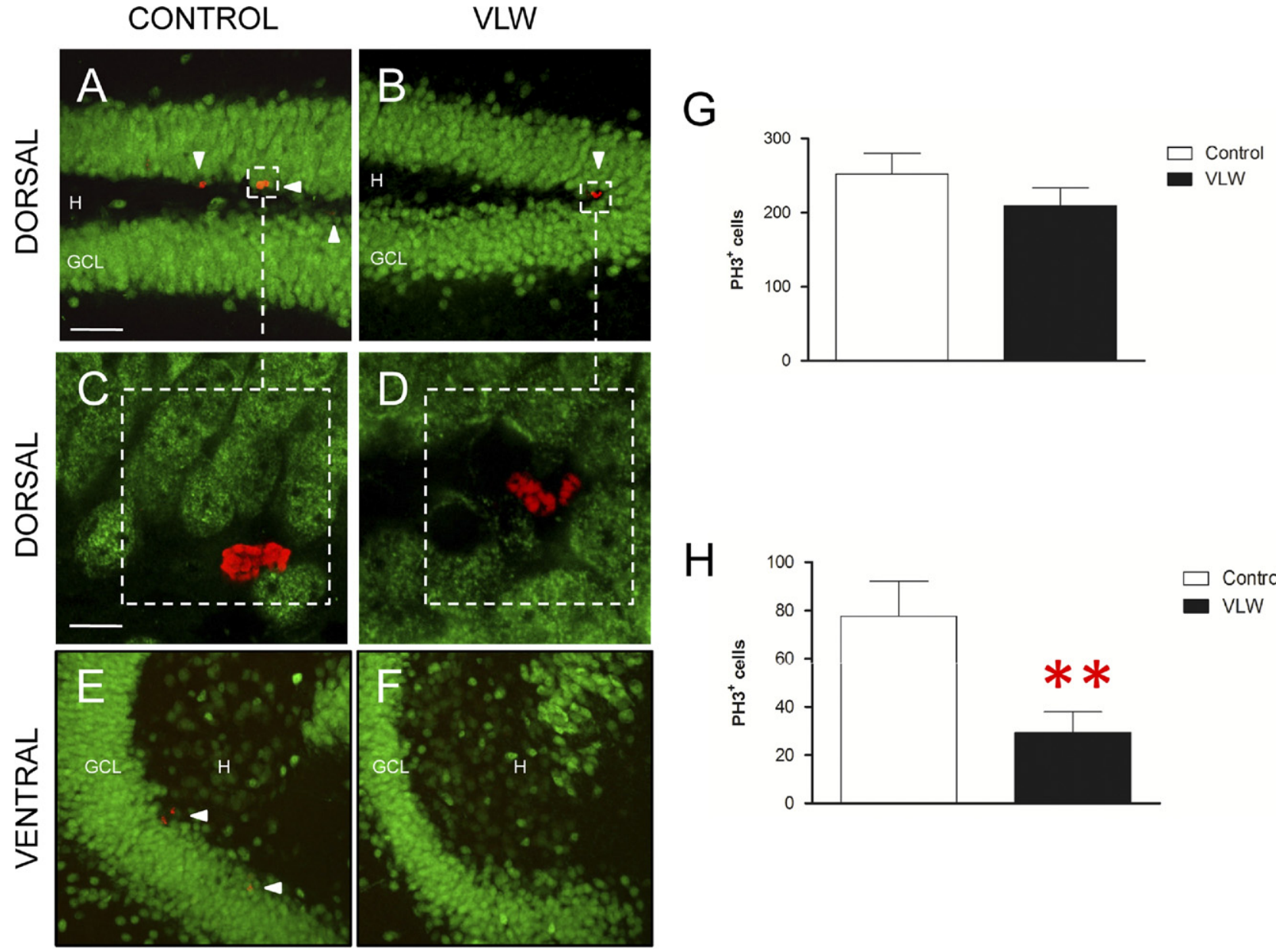

$\mathrm{H}$
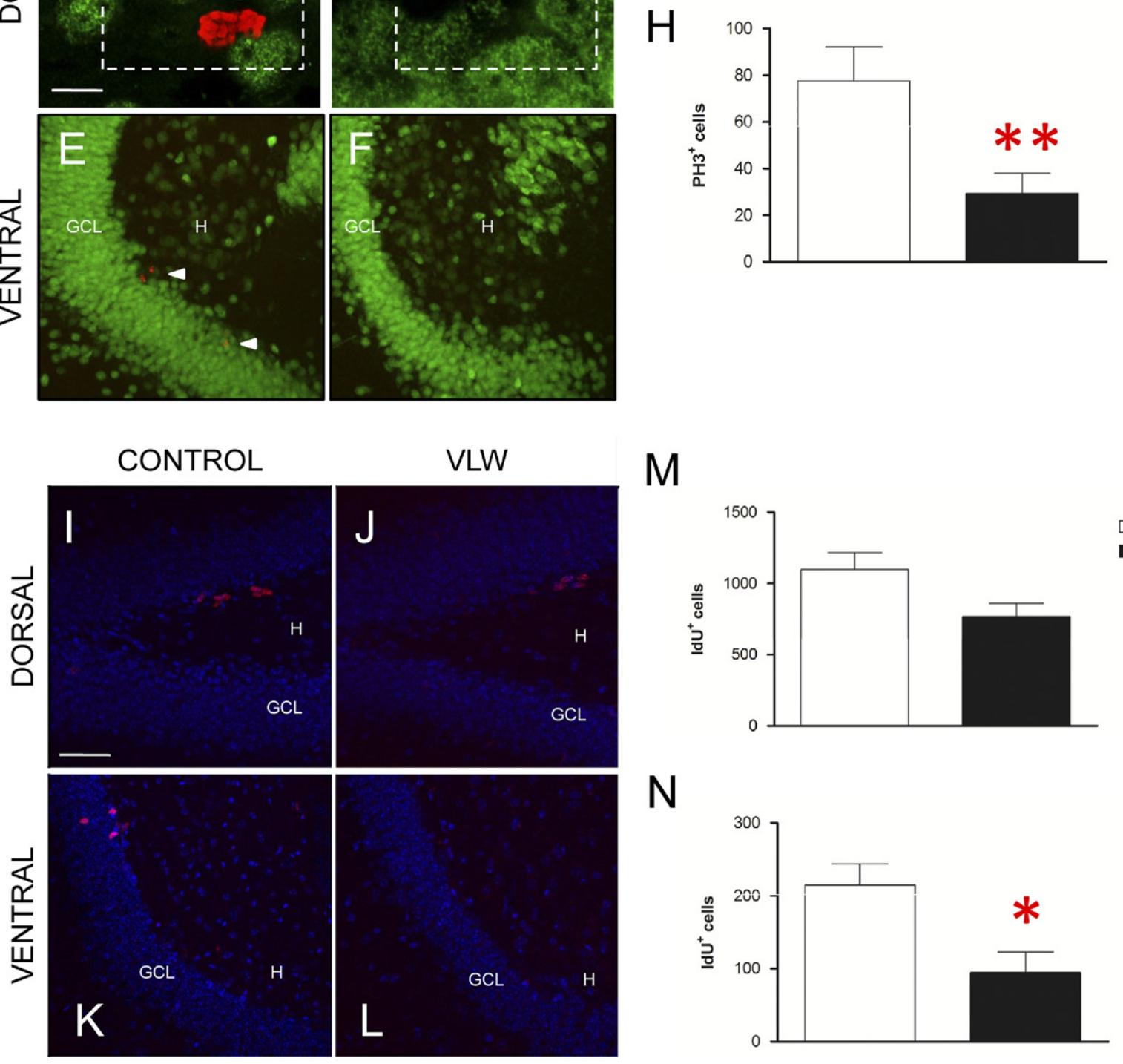

M

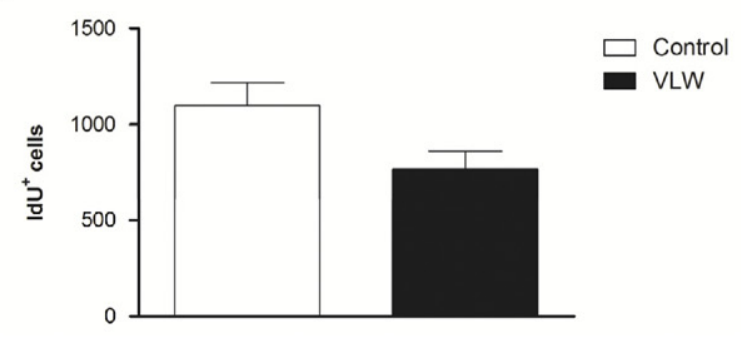

$\mathrm{N}$

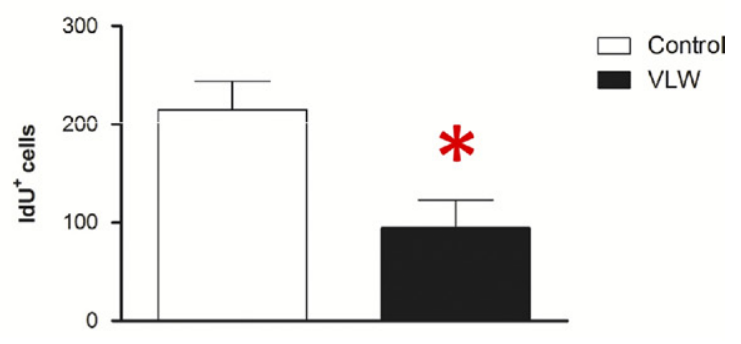

Fig. 3. Proliferation and early survival of granule neuron precursors is only affected in the ventral dentate gyrus (DG) of Tau VLW mice. (A-H) The mitotic marker phosphor-histone $3(\mathrm{PH} 3)$. (A-F) Representative images of dorsal and ventral DG showing that tau ${ }^{\mathrm{L} W}{ }^{\text {mice }}(\mathrm{B}, \mathrm{D}, \mathrm{F})$ have fewer PH3 ${ }^{+}$ cells in the ventral DG than control animals (A, C, E). Red: PH3. Green: NeuN. Scale bar: $50 \mu \mathrm{m}(\mathrm{A}, \mathrm{B}, \mathrm{E}, \mathrm{F})$ or $10 \mu \mathrm{m}(\mathrm{C}, \mathrm{D})$. (G, H) Quantification 
marily due to changes in proliferation but not in net survival, at least at this early time point.

\section{Neuronal death in the dorsal and ventral DG of tau $^{\mathrm{VLW}}$ and wt mice}

We measured apoptotic neuronal death in the DG of transgenic and wild type mice by assessing the amount of fractin, an actin fragment produced by caspase 3 cleavage that is commonly used as a marker of apoptotic cells (Dupret et al., 2007). When the number of fractin positive cells was quantified, there was a clear increase in cell death in both the dorsal $\left(F_{1,19}=10.689, P=0.004\right)$ and ventral $\left(F_{1,16}=3.981, P=0.065\right)$ DG of transgenic mice when compared with the wild type mice (Fig. $4 \mathrm{~A}-\mathrm{H})$. In light of the decrease in cell proliferation observed, these findings suggest cell survival is poorer in transgenic mice (higher cell death), although this cannot account for the relative differences in cell number between dorsal and ventral regions (see Fig. 2). Based on these findings, we propose that the decreased volume of the ventral DG in transgenic mice is provoked by the combination of less cell proliferation and more cell death.

To investigate the possibility that differences in neuronal maturation may underlie the differences observed in DG volume between wt and transgenic mice, we quantified the number of inactive immature neurons in the DG using antibodies directed against DCX and calretinin. Calretinin is transiently expressed by postmitotic immature neurons in the dentate gyrus during AHN (Brandt et al., 2003), whereas doublecortin is widely used as a marker of immature neurons during AHN. Combining these two markers enables neuroblasts that are actively proliferating or that are inactive to be distinguished (Llorens-Martín et al., 2006, 2010), with cells positive for both markers indicating postmitotic differentiating neurons. A decrease in the number of cells positive for both DCX and calretinin was observed in dorsal $\left(F_{1,19}=20.767, P<0.001\right)$ and ventral $\left(F_{1,15}=7.383, P=0.017\right) \mathrm{DG}$ regions of transgenic versus wild type mice (Fig. 4I-P), indicating a decrease in the number of immature neuronal precursors in both regions. However, this decrease did not appear to account for the observed differences in the volume of the ventral region in transgenic versus wild type mice.

Tau hyperphosphorylation at sites recognized by AT8 or PHF-1 antibodies is indicative of neuron undergoing neurodegeneration. AT8 mainly identifies human rather than murine Tau protein, and it has been previously demonstrated that mice overexpressing human tau exhibit Tau phosphorylation at AT8 site (Pérez et al., 2005; Engel et al., 2006). On the other hand, it should be noted that only murine and not human-mutated tau can be recognized by PHF-1, as the R408W mutation in human tau prevents phosphorylation at the PHF-1 site (Pérez et al., 2000). We have determined the percentage of $\mathrm{DCX}^{+}$cells that showed Tau phosphorylation at PHF-1 site. Our results show a significant increase in the number of $\mathrm{DCX}^{+} /$ PHF- $1^{+}$neurons in the ventral $\left(F_{1,19}=4.84 ; P=0.042\right)$ but not the dorsal $\left(F_{1,19}=0.024 ; P=0.879\right) D G$ of transgenic when compared with the wt mice (see Fig. $5 A-N$ ). These results also suggest that not only those neurons expressing exogenous human tau but also those expressing endogenous murine tau could undergo degeneration.

\section{GABAergic innervation augments in the molecular layer of the dorsal dentate gyrus in Tau ${ }^{\mathrm{VLW}}$ mice}

Our previous data suggest that the ventral DG region is more vulnerable than the dorsal region to the reported toxic effects of tau ${ }^{\vee L W}$ (Lim et al., 2001). Hence, we investigated the possible causes of this vulnerability and whether neurodegeneration does indeed begin in the ventral DG region. Hippocampal GABAergic afferent innervation has been proposed to exert a neuroprotective influence and thus, we measured the area occupied by GABAergic terminals in the molecular layer to determine whether differences in innervation could account for a neuroprotective effect in the dorsal but not the ventral blade of the dentate gyrus. Indeed, GABAergic innervation did augment in the dorsal dentate gyrus of tau ${ }^{\vee L W}$ when compared with the wt mice $\left(F_{1,19}=3.359, P=0.076\right)$ but not in the ventral dentate gyrus $\left(F_{1,19}=0.286, P=0.600\right.$ : Fig. $6 A-F)$.

\section{Depressive-like behavior is altered in tau ${ }^{\mathrm{VLw}}$ mice}

Porsolt test was carried out, and the time mice spent immobile during the second day was quantified, and represented as a percentage of total time. Accordingly, it was clear that the transgenic tau ${ }^{\mathrm{LW}}$ animals spent significantly longer immobile in this Porsolt test than their wild type counterparts ( $P=0.001$ : Fig. $7 \mathrm{~A})$. On the contrary, time animals spent climbing was significantly reduced in tauVLW mice ( $P=0.001$ : Fig. $7 \mathrm{~B})$. Swimming time was not modified in transgenic compared with wt animals $(P=0.628$ : Fig. $7 C)$.

\section{DISCUSSION}

In the present study, we found that overexpression of human tau resulted in a decrease of the dentate gyrus's ventral blade. An earlier study indicated that the absence of tau did not affect the DG (Gómez de Barreda et al., 2010), and indeed, the overexpression of the mutant human tau did not alter the volume of the dorsal DG (Engel et al., 2006). As human tau is expressed under the Thy 1 promoter, the different effects in dorsal or ventral regions

of $\mathrm{PH}^{+}$cells. Tau ${ }^{\mathrm{VLW}}$ mice exhibit a selective decrease in the number of $\mathrm{PH}^{+}$cells in the ventral $(\mathrm{H})$ but not the dorsal (G) DG. (I-N) Early survival $(24 \mathrm{~h})$ of granule neuron precursors after IdU injection ( $24 \mathrm{~h}$ before sacrifice). (I-L) Representative images of IdU staining in the dorsal and ventral DG showing that fewer IdU ${ }^{+}$cells survive in the ventral DG of tau ${ }^{\mathrm{VLW}}$ mice $(\mathrm{L})$ than in control mice $(\mathrm{K})$, whereas no differences can be observed in the dorsal blade between control (I) and tau ${ }^{\mathrm{VLW}}$ mice (J). Red: IdU. Blue: DAPI. Scale bar: $50 \mu \mathrm{m}$. (M-N) Quantification of the IdU ${ }^{+}$cells demonstrates that tau ${ }^{\mathrm{VLW}}$ mice exhibit a selective loss of these cells in the ventral (N) but not the dorsal DG (M). H, hilus. GCL, granule cell layer. For interpretation of the references to color in this figure legend, the reader is referred to the Web version of this article. ${ }^{*} 0.05>P>0.01 ;{ }^{* *} 0.01>P>0.001$. 

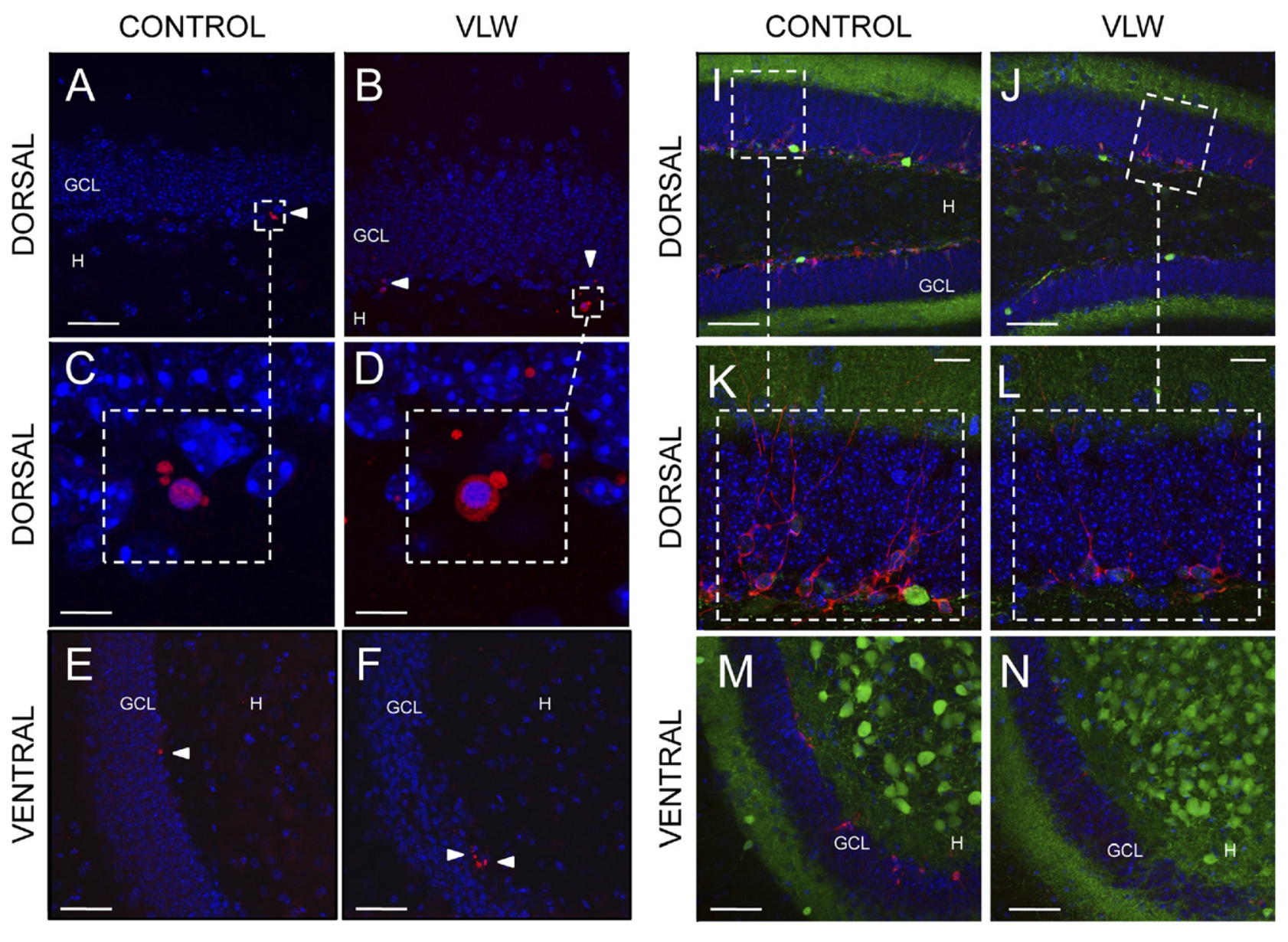

G

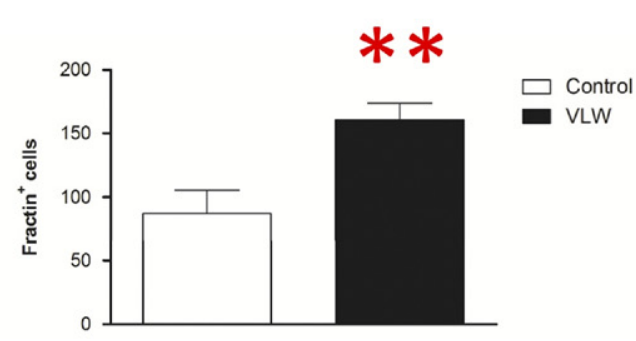

$\mathrm{O}$

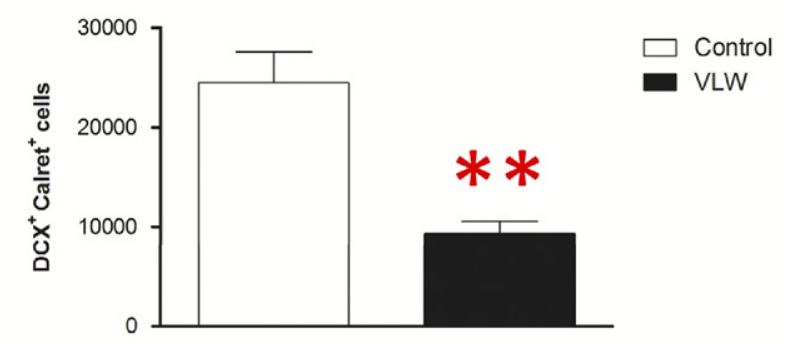

\section{$\mathrm{H}$}
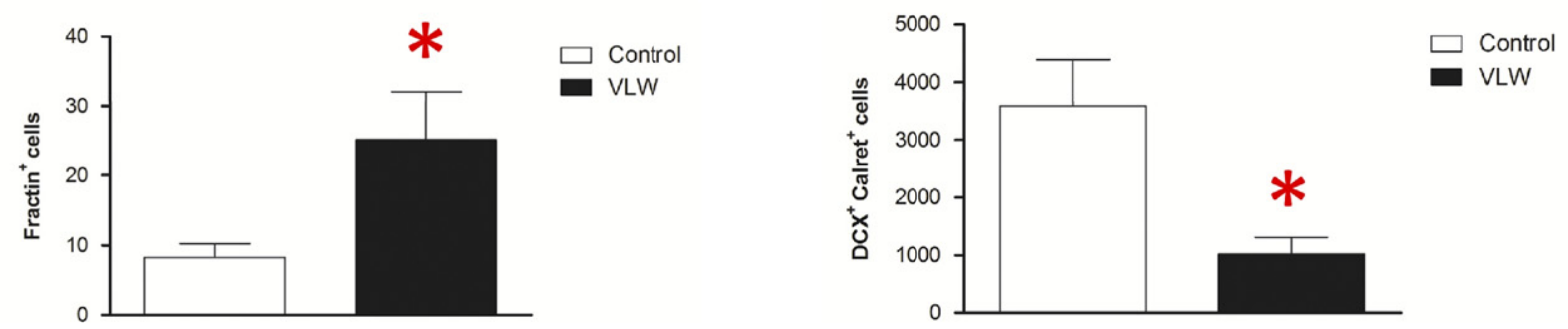

Fig. 4. Both apoptosis and the total number of immature neurons are altered in Tau ${ }^{V L W}$ mice. (A-F) The marker of apoptosis, fractin. (A-F) Representative images of dorsal and ventral DG fractin staining showing tau ${ }^{\vee L W}$ mice $(B, D, F)$ have more fractin ${ }^{+}$cells than control animals $(A, C$, E). (C, D) High magnification images representing apoptotic cell morphology from (A) and (B) selected areas, respectively (white square, broken line). 

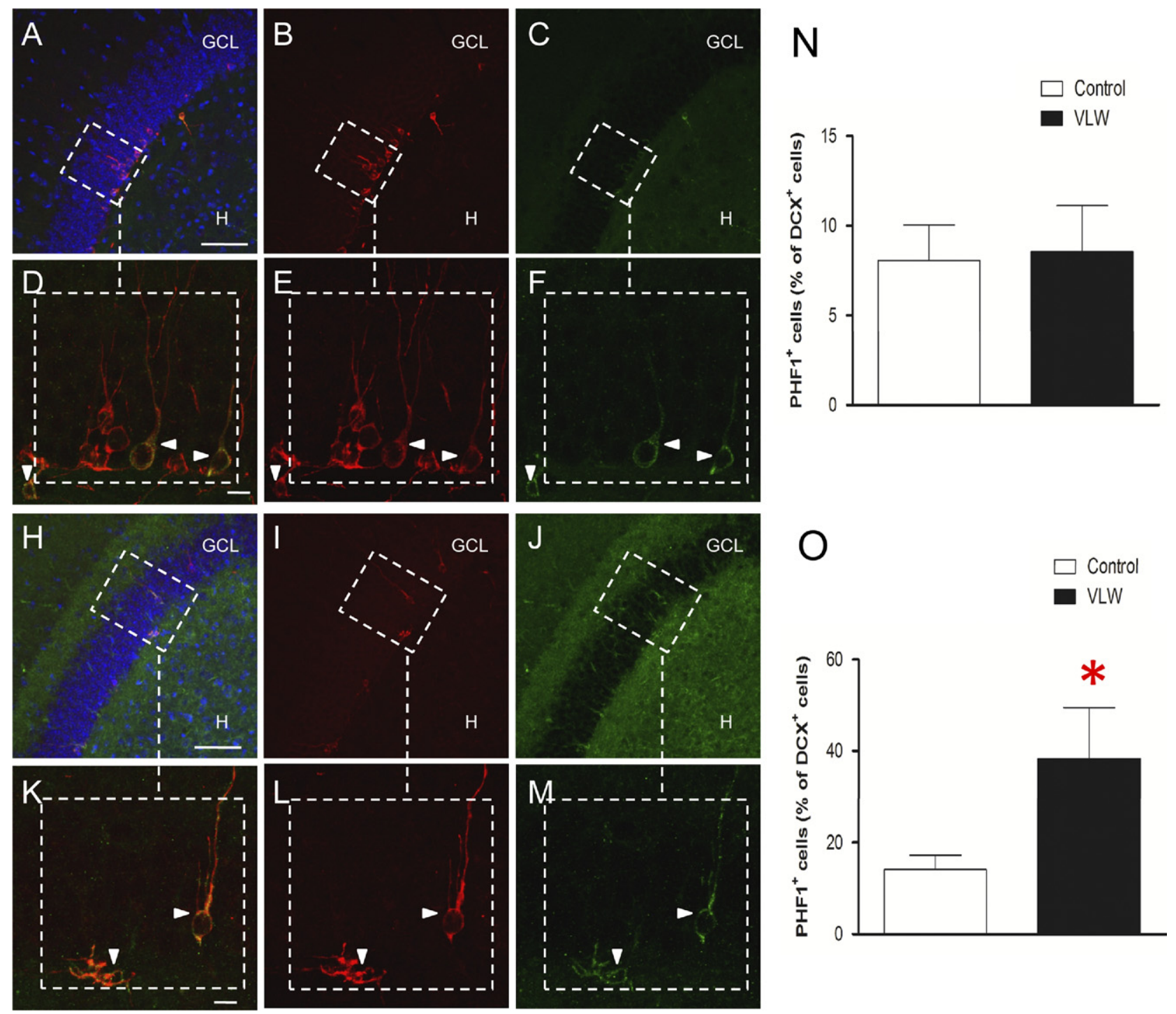

Fig. 5. Tau ${ }^{\mathrm{VLW}}$ mice have more hyperphosphorylated tau (PHF-1) in the ventral blade of the dentate gyrus. (A-N) Expression of the hyperphosphorylated PHF-1 Tau isoform by immature $\mathrm{DCX}^{+}$neurons. (A-C, H-J) Representative images of the DG and respective magnifications (D, E, K-M) showing how more $\mathrm{DCX}^{+}$cells express the hyperphosphorylated Tau isoform PHF-1 in the ventral DG of tau ${ }^{\mathrm{VLW}}$ mice $(\mathrm{H}-\mathrm{M})$ when compared with control animals (A-F). Red: DCX. Green: PHF-1. Scale bar: $50 \mu \mathrm{m}(\mathrm{A}-\mathrm{C}, \mathrm{H}-\mathrm{J})$ or $10 \mu \mathrm{m}(\mathrm{D}-\mathrm{F}, \mathrm{K}-\mathrm{M})$. (N, O) Quantification of PHF-1+/DCX+ cells showing the percentage of $\mathrm{PHF}-1^{+}$cells relative to the total number of $\mathrm{DCX}^{+}$cells. The percentage of $\mathrm{PHF}-1^{+}$cells in ventral $(\mathrm{O})$, but not the dorsal $(\mathrm{N})$, DG is significantly higher in Tau ${ }^{\mathrm{VLW}}$ mice. $\mathrm{H}$, hilus. GCL, granule cell layer. For interpretation of the references to color in this figure legend, the reader is referred to the Web version of this article. ${ }^{*} 0.05>P>0.01$.

of the DG may reflect differences in the expression of the protein in either region. However, this appears unlikely based on the comparable levels of expression of the Thy 1 promoter in the dorsal and ventral blades of the dentate gyrus (Vuksic et al., 2008), and the similar levels of expression of human tau observed in both DG regions here. Alternatively, the differential responses to tau overexpres- sion may reflect the distinct structural and functional characteristics of each area (Fanselow and Dong, 2010). The accumulation of hyperphosphorylated tau is a useful marker of this vulnerability, as it identifies neurons with preliminary damage (Hernández et al., 2003). Indeed, the presence of hyperphosphorylated tau is an early event in the evolution of the tau-pathology in neurodegenerative

Scale bar: $50 \mu \mathrm{m}$ in (A, B); $10 \mu \mathrm{m}$ in (C, D). Red: Fractin. Blue: DAPI. Scale bar: $50 \mu \mathrm{m}$. (G, H) When quantified, Tau ${ }^{\mathrm{VLW}}$ mice exhibit more fractin ${ }^{+}$ cells in both the ventral (H) and dorsal (G) DG. (I-P) Newborn neuron markers: doublecortin (DCX) and calretinin. (I-N) Representative images of dorsal (I-L) and ventral (M, N) DG double-stained for DCX/Calretinin, showing that tau ${ }^{\mathrm{VLW}}$ mice (J, L, M) have fewer DCX $/$ calretinin $^{+}$cells than control animals (I, K, M) both in dorsal and ventral DG. Red: DCX. Green: calretinin. Blue: DAPI. Scale bar: $50 \mu \mathrm{m}(\mathrm{I}, \mathrm{J}, \mathrm{M}, \mathrm{N})$ and $20 \mu \mathrm{m}(\mathrm{K}, \mathrm{L})$. (O, P) Quantification of $\mathrm{DCX}^{+} /$calretinin $^{+}$cells showing that TauvLw mice have fewer DCX ${ }^{+} / \mathrm{Calret}^{+}$cells in both the ventral $(P)$ and dorsal $(\mathrm{O}) \mathrm{DG}$. H, hilus. $\mathrm{GCL}$, granule cell layer. For interpretation of the references to color in this figure legend, the reader is referred to the Web version of this article. ${ }^{*} 0.05$ $>\mathrm{P}>0.01 ;{ }^{* *} 0.01>\mathrm{P}>0.001$. 

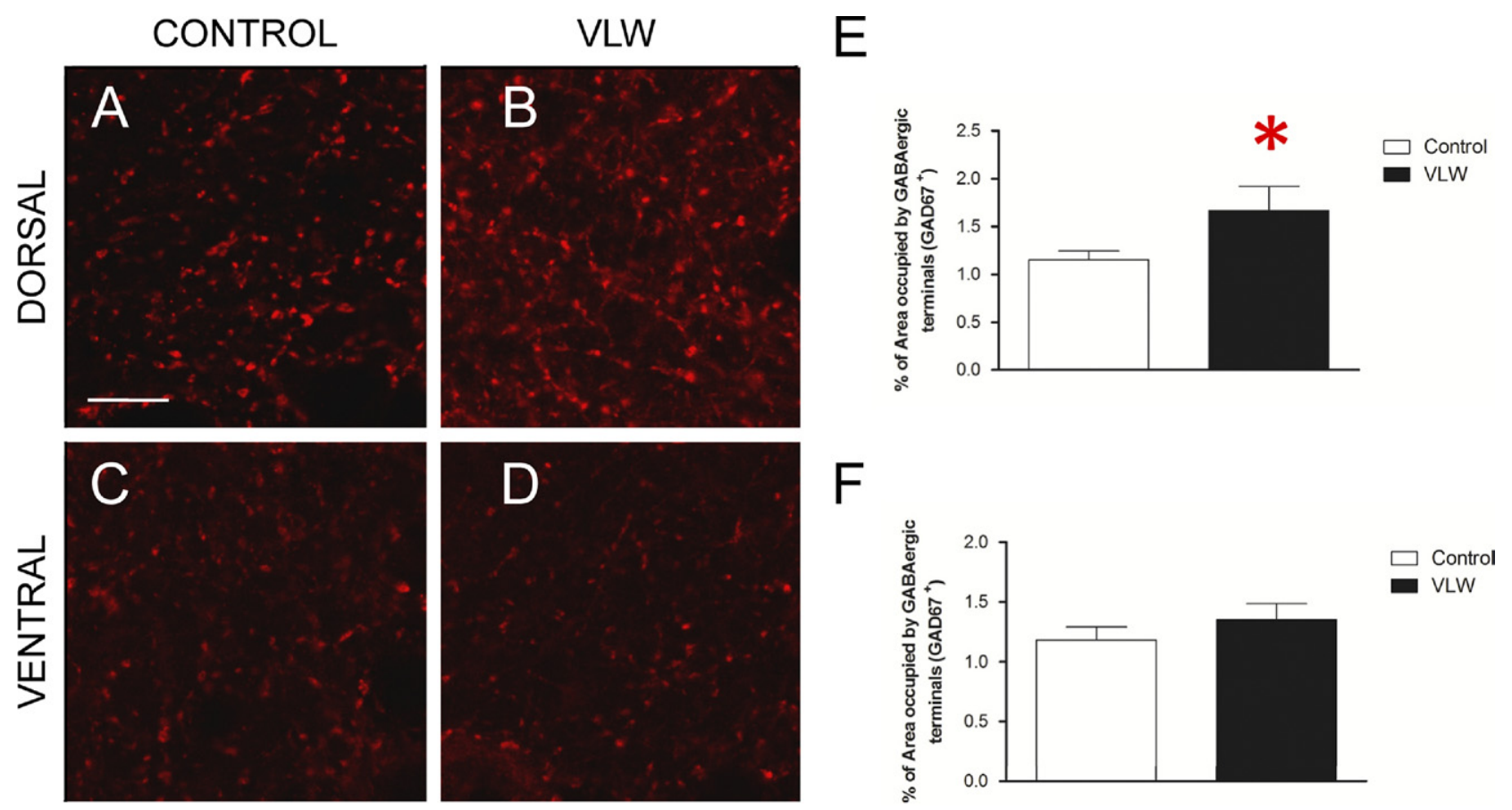

Fig. 6. Increased GABAergic innervation in dorsal blade of the dentate gyrus in Tau ${ }^{\mathrm{L} W}$ mice show. (A-F). Area occupied by GABAergic terminals $\left(G A D 65^{+}\right)$in the molecular layer. (A-D) Representative images of the dorsal and ventral DG showing how the area occupied by GABAergic terminals $\left(G A D 65^{+}\right)$is greater in tau ${ }^{\mathrm{VLW}}$ mice $(B, D)$ than in control $(A, C)$ mice. Red: GAD65. Scale bar: $10 \mu \mathrm{m}$. (E, F) Quantification of the area occupied by GABAergic terminals $\left(\mathrm{GAD}^{+} 5^{+}\right.$) in the molecular layer. It should be noted that this parameter does not vary in the ventral blade of the dentate gyrus of Tau ${ }^{V L W}$ mice $(F)$. However, the GABAergic innervation increases in the dorsal blade of Tau ${ }^{V L W}$ when compared with wild type mice (E). For interpretation of the references to color in this figure legend, the reader is referred to the Web version of this article. ${ }^{*} 0.05>\mathrm{P}>0.01$.

diseases like Alzheimer's disease (Braak et al., 1994). Accordingly, the expression of hypherphosphorylated tau was greater in immature neurons of the ventral dentate gyrus, which may be indicative of premature damage to this neuronal population.

As in the hippocampus, the dorsal and ventral regions of the DG may fulfill distinct functions. Indeed, the dorsal DG has been proposed to mediate primarily cognitive functions (van Praag et al., 1999), whereas the ventral DG is implicated in stress and emotional behavior (Sahay and Hen, 2007). Distinct inputs and outputs have also been proposed for the dorsal and ventral dentate gyrus (Fanselow and Dong, 2010) as occurs in the dorsal and ventral hippocampus (Swanson and Cowan, 1977). Moreover, differences in gene expression have been described in both regions, for example the lct gene is preferentially expressed in the dorsal DG, whereas the trhr gene is expressed specifically at the ventral region (Fanselow and Dong, 2010) (see also Allen Brain Atlas: http://www.brainmap.org). Furthermore, we observed clear behavioral differences in transgenic mice in the Porsolt test (increased Immobility time and reduced Climbing time), although they did not appear to suffer altered memory functions when such studies were carried out on animals of similar ages (Engel et al., 2006). As has been previously described, tau R406W transgenic mice, bearing one of the three mutations of tau ${ }^{\mathrm{VLW}}$ mice showed no anxious behavior in dark/ ligth test compared with wt animals even at 12-14 months of age (Egashira et al., 2005). Additionally, selective sero- tonin recapture inhibitors as fluvoxamine exert possitive effects on depressive-like behavior of R406W mice, whereas noradrenalin recapture inhibitors had no effect. Once anxiety-like components can be discarded, Porsolt test is considered to be a robust indicator of depressivelike behavior (Porsolt et al., 1977). Additionally, an exhaustive study of motor function developed in R406W mice showed no motor alterations in rotarod test even at 12-14 months of age (Egashira et al., 2005). However, some alterations in the object recognition test have been reported in animals older than 8 months (Navarro et al., 2008).

Based on the present findings, the main consequence of human tau overexpression found in the ventral dentate gyrus is a decrease in the proliferation of the neuronal precursor cells and an increase in cell death accompanied by a reduction in differentiation and survival rate. As elegantly reviewed by Boekhoorn et al., AHN alterations in different animal models of $A D$ show alterations ranging from increases in proliferation and DCX-expressing cells to neuroblast depletion (Kuhn et al., 2007). Tau protein plays a crucial role on neuronal processes related to hippocampal learning and memory (Kuhn et al., 2007). When translating results obtained from murine models to human $A D$ pathology, a tremendous controversy emerges, since only one work by Jin et al. (2004) reported increased DCX expression in postmortem human $\mathrm{AD}$ tissue. Other authors found changes in proliferation rate neither in human presenile AD samples (Boekhoorn et al., 2006a) nor in a 

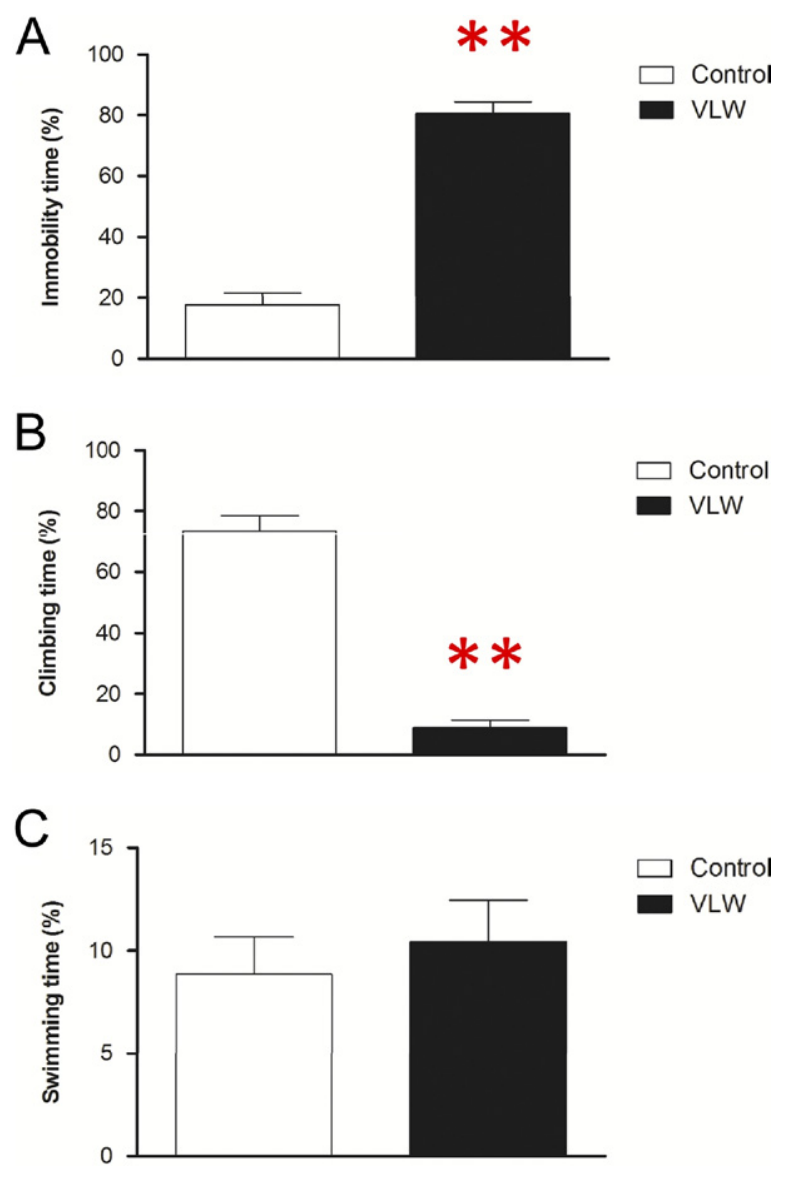

Fig. 7. Depressive-like behavior of tau ${ }^{\mathrm{VLW}}$ mice. The time spent immobile in the Porsolt test performed on the second day (percentage of time immobile/total time). The significant increase in the time spent immobile indicates that Tau ${ }^{\mathrm{VLW}}$ mice show a pronounced depressivelike behavior when compared with control animals (A). Accordingly, time animals spent climbing was significantly reduced in tau ${ }^{\mathrm{VLW}}$ mice (B). Swimming time was not modified in transgenic compared with wt animals (C). For interpretation of the references to color in this figure legend, the reader is referred to the Web version of this article. ${ }^{* *} 0.01$ $>\mathrm{P}>0.001$.

murine model of taupathy bearing P301 mutation (Boekhoorn et al., 2006b). Our results regarding the lack of changes in proliferation rate in the dorsal dentate gyrus (the bigger part of the structure) correlate with the results obtained by Boekhoorn et al. However, other models of P301S mutated human tau showed overexpression of the cell cycle-dependent kinase inhibitors p21/Cip1 and p27/ Kip1 (Delobel et al., 2006) as well as cell cycle arrest (Zhao et al., 2003). Differences in promoter efficiency, or regional- and cell-lineage-linked expression level differences may account for the putative discrepancies observed in these different animal models. The decrease in proliferation found in this work appears to mediate the specific reduction in the volume of the ventral DG. The volume of the DG depends on the number of cells present in this structure, which is likely to be strongly influenced by the equilibrium between the number of dying cells and the number of new neurons generated by proliferation and $A H N$. Indeed, the effects of the decrease in cell prolifera- tion in the ventral DG of transgenic mice were probably exacerbated by an increase in cell death in both the dorsal and ventral regions, which may further contribute to the overall decrease in ventral DG volume. Regarding the differences between apoptotic rate data (increased in both the dorsal and the ventral blade of the dentate gyrus) and dentate gyrus volume reduction (only found in the ventral blade), it is important to note that dentate gyrus volume could not only be affected by the total number of mature (and immature) neurons. Also, nucleus and cytoplasm size, volume occupied by dendritic trees and/or axonal terminals can account for variations in the volume of the structure. It is also not surprising that an increase in apoptosis rate could not be reflected in the volume of the structure if it is not accompanied by parallel reductions in proliferation rate (as does occur in the ventral blade). Since only apoptosis is increased in the dorsal blade (but proliferation rate is not modified), it could be possible that additional and cumulative increased apoptosis maintained during longer periods was necessary to produce changes in the total volume of the structure. Additionally, total number of mature neurons is significantly higher in dorsal blade compared with ventral blade, even in a wt mouse, so, it seems reasonable that an increase in apoptotic rate should have a more drastic impact on dentate gyrus ventral blade than on the dorsal blade volume. But, of course, the possibility that dorsal blade volume could be affected after longer periods (even though proliferation rate was not affected) cannot be ruled out. It has been suggested that the endogenous population of mature granule neurons, as well as the subgranular layer vascular niche, are involved in maintaining the integrity and appropriate adult hippocampal neurogenesis rate of the dentate gyrus (Fabel et al., 2003; Llorens-Martín et al., 2006). Accordingly, increases in $\mathrm{DCX}^{+}$cells resulting from physical activity are correlated with mature granule neuron density (LlorensMartín et al., 2006). Similarly, we propose that the endogenous population of mature granule neurons plays an important role in maintaining an appropriate rate of AHN under pathological conditions. The thy1 promoter used in the mouse model studied is only expressed in mature granule neurons, the only cells that can overexpress human tau ${ }^{\mathrm{LLW}}$ at levels detectable by immunohistochemistry (Vuksic et al., 2008). We hypothesize that the decrease in mature granule neuron density provoked by the pathological overexpression of toxic mutant human tau is more pronounced in areas with less dense endogenous mature granule neurons, such as the ventral blade of the dentate gyrus. Hence, the impact of the decrease in mature neuron density on the rate of AHN would be stronger in the ventral than in the dorsal region of the dentate gyrus. The possibility of degeneration of the dorsal dentate gyrus at more advanced ages cannot be ruled out, although our results clearly suggest a greater sensitivity of the ventral dentate gyrus to overexpression of an aberrant tau isoform.

While overexpression of tau ${ }^{\mathrm{LW}}$ has a toxic effect on neurons (Lim et al., 2001), this toxicity may be offset by the activation of neuroprotective factors as part of a compensatory response. A neuroprotective role for afferent 
GABAergic hippocampal innervation has been suggested in several physiological and pathological conditions (Gutiérrez and Heinemann, 2006). Indeed, we found an increase in the area occupied by GABAergic terminals in the dorsal molecular layer of the dentate gyrus of tau $\mathrm{VLW}$ mice. This increase does not occur in the ventral zone. This fact may contribute, among other neuroprotective and neurotoxic factors, to the observed dentate gyrus's ventral blade faster degeneration reported in this study. Although further investigation is needed, we suggest that increased GABAergic innervation could be a neuroprotective factor increased in the dorsal blade of the dentate gyrus, delaying or even preventing the structural degeneration of this area associated to tau ${ }^{\mathrm{LLW}}$ overexpression. However, other neuroprotective factors could also be reduced in the ventral compared with dorsal blade per se, and this putative increase in GABAergic innervation could not take place in the ventral blade of the DG, or at least might be insufficient to prevent premature neurodegeneration of this structure.

The findings presented here may be relevant for the treatment of certain neurodegenerative disorders and other mental illnesses such as Major depression. Indeed, if this neuroprotective role exerted by GABAergic innervation was further confirmed, potentiators of GABAergic transmission (or glutamatergic antagonists) could be administrated locally to ventral blade of the dentate gyrus to maintain an appropriate rate of $\mathrm{AHN}$, thereby preventing premature neurodegeneration in this structure.

Acknowledgments_- This study was funded by grants from the Spanish Ministry of Health (SAF 2006-02424), Comunidad de Madrid (SAL/0202/2006), Fundación M. Botín and an institutional grant from Fundación R. Areces.

\section{REFERENCES}

Alonso AD, Di Clerico J, Li B, Corbo CP, Alaniz ME, Grundke-lqbal I, lqbal K (2010) Phosphorylation of tau at Thr212, Thr231, and Ser262 combined causes neurodegeneration. J Biol Chem 285:30851-30860.

Andorfer C, Acker CM, Kress Y, Hof PR, Duff K, Davies P (2005) Cell-cycle reentry and cell death in transgenic mice expressing nonmutant human tau isoforms. J Neurosci 25:5446-5454.

Avila J, Lucas JJ, Perez M, Hernandez F (2004) Role of tau protein in both physiological and pathological conditions. Physiol Rev 84:361-384.

Boekhoorn K, Joels M, Lucassen PJ (2006a) Increased proliferation reflects glial and vascular-associated changes, but not neurogenesis in the presenile Alzheimer hippocampus. Neurobiol Dis 24:1-14.

Boekhoorn K, Terwel D, Biemans B, Borghgraef P, Wiegert O, Ramakers GJ, de Vos K, Krugers $\mathrm{H}$, Tomiyama T, Mori H, Joels $\mathrm{M}$, van Leuven F, Lucassen PJ (2006b) Improved long-term potentiation and memory in young tau-P301L transgenic mice before onset of hyperphosphorylation and tauopathy. J Neurosci 26:3514-3523.

Braak E, Braak H, Mandelkow EM (1994) A sequence of cytoskeleton changes related to the formation of neurofibrillary tangles and neuropil threads. Acta Neuropathol 87:554-567.

Brandt MD, Jessberger S, Steiner B, Kronenberg G, Reuter K, BickSander A, von der Behrens W, Kempermann G (2003) Transient calretinin expression defines early postmitotic step of neuronal differentiation in adult hippocampal neurogenesis of mice. Mol Cell Neurosci 24:603-613.
Caceres A, Kosik KS (1990) Inhibition of neurite polarity by tau antisense oligonucleotides in primary cerebellar neurons. Nature 343:461-463.

Dawson HN, Ferreira A, Eyster MV, Ghoshal N, Binder LI, Vitek MP (2001) Inhibition of neuronal maturation in primary hippocampal neurons from tau deficient mice. J Cell Sci 114:1179-1187.

de Barreda EG, Dawson HN, Vitek MP, Avila J (2010) Tau deficiency leads to the upregulation of BAF-57, a protein involved in neuronspecific gene repression. FEBS Lett 584:2265-2270.

Delobel P, Lavenir I, Ghetti B, Holzer M, Goedert M (2006) Cell-cycle markers in a transgenic mouse model of human tauopathy: increased levels of cyclin-dependent kinase inhibitors p21Cip1 and p27Kip1. Am J Pathol 168:878-887.

Deng W, Aimone JB, Gage FH (2010) New neurons and new memories: how does adult hippocampal neurogenesis affect learning and memory? Nat Rev Neurosci 11:339-350.

Detke MJ, Wieland S, Lucki I (1995) Blockade of the antidepressantlike effects of 8-OH-DPAT, buspirone and desipramine in the rat forced swim test by $5 \mathrm{HT} 1 \mathrm{~A}$ receptor antagonists. Psychopharmacology (Berl) 119:47-54.

Dupret D, Fabre A, Döbrössy MD, Panatier A, Rodríguez JJ, Lamarque S, Lemaire V, Oliet SH, Piazza PV, Abrous DN (2007) Spatial learning depends on both the addition and removal of new hippocampal neurons. PLoS Biol 5:e214.

Egashira N, Iwasaki K, Takashima A, Watanabe T, Kawabe H, Matsuda T, Mishima K, Chidori S, Nishimura R, Fujiwara M (2005) Altered depression-related behavior and neurochemical changes in serotonergic neurons in mutant R406W human tau transgenic mice. Brain Res 1059:7-12.

Engel T, Lucas JJ, Gómez-Ramos P, Moran MA, Avila J, Hernández F (2006) Cooexpression of FTDP-17 tau and GSK-3beta in transgenic mice induce tau polymerization and neurodegeneration. Neurobiol Aging 27:1258-1268.

Fabel K, Fabel K, Tam B, Kaufer D, Baiker A, Simmons N, Kuo CJ, Palmer TD (2003) VEGF is necessary for exercise-induced adult hippocampal neurogenesis. Eur J Neurosci 18:2803-2812.

Fanselow MS, Dong HW (2010) Are the dorsal and ventral hippocampus functionally distinct structures? Neuron 65:7-19.

Goedert M, Spillantini MG (2000) Tau mutations in frontotemporal dementia FTDP-17 and their relevance for Alzheimer's disease. Biochim Biophys Acta 1502:110-121.

Gómez de Barreda E, Pérez M, Gómez Ramos P, de Cristobal J, Martín-Maestro P, Morán A, Dawson HN, Vitek MP, Lucas JJ, Hernández F, Avila J (2010) Tau-knockout mice show reduced GSK3-induced hippocampal degeneration and learning deficits. Neurobiol Dis 37:622-629.

Gutiérrez R, Heinemann U (2006) Co-existence of GABA and Glu in the hippocampal granule cells: implications for epilepsy. Curr Top Med Chem 6:975-978.

Harada A, Oguchi K, Okabe S, Kuno J, Terada S, Ohshima T, SatoYoshitake R, Takei Y, Noda T, Hirokawa N (1994) Altered microtubule organization in small-calibre axons of mice lacking tau protein. Nature 369:488-491.

Hernández F, Lucas JJ, Cuadros R, Avila J (2003) GSK-3 dependent phosphoepitopes recognized by PHF-1 and AT- 8 antibodies are present in different tau isoforms. Neurobiol Aging 24:1087-1094.

Hutton M, Lendon CL, Rizzu P, Baker M, Froelich S, Houlden H, Pickering-Brown S, Chakraverty S, Isaacs A, Grover A, Hackett J, Adamson J, Lincoln S, Dickson D, Davies P, Petersen RC, Stevens $M$, de Graaff E, Wauters E, van Baren J, Hillebrand M, Joosse M, Kwon JM, Nowotny P, Che LK, Norton J, Morris JC, Reed LA, Trojanowski J, Basun H, Lannfelt L, Neystat M, Fahn S, Dark F, Tannenberg T, Dodd PR, Hayward N, Kwok JB, Schofield PR, Andreadis A, Snowden J, Craufurd D, Neary D, Owen F, Oostra BA, Hardy J, Goate A, van Swieten J, Mann D, Lynch T, Heutink P (1998) Association of missense and 5'-splice-site mutations in tau with the inherited dementia FTDP-17. Nature 393:702-705. 
Jin K, Peel AL, Mao XO, Xie L, Cottrell BA, Henshall DC, Greenberg DA, 2004) Increased hippocampal neurogenesis in Alzheimer's disease. Proc Natl Acad Sci U S A 101(1):343-347.

Knoth R, Singec I, Ditter M, Pantazis G, Capetian P, Meyer RP, Horvat V, Volk B, Kempermann G (2010) Murine features of neurogenesis in the human hippocampus across the lifespan from 0 to 100 years. PLoS One 5:e8809.

Kuhn HG, Cooper-Kuhn CM, Boekhoorn K, Lucassen PJ (2007) Changes in neurogenesis in dementia and Alzheimer mouse models: are they functionally relevant? Eur Arch Psychiatry Clin Neurosci 257:281-289.

Lim F, Hernández F, Lucas JJ, Gómez-Ramos P, Morán MA, Avila J (2001) FTDP-17 mutations in tau transgenic mice provoke lysosomal abnormalities and Tau filaments in forebrain. Mol Cell Neurosci 18:702-714.

Llorens-Martín M, Tejeda GS, Trejo JL (2010) Differential regulation of the variations induced by environmental richness in adult neurogenesis as a function of time: a dual birthdating analysis. PLoS One 5:e12188.

Llorens-Martín M, Torres-Alemán I, Trejo JL (2006) Pronounced individual variation in the response to the stimulatory action of exercise on immature hippocampal neurons. Hippocampus 16:480-490.

Navarro P, Guerrero R, Gallego E, Avila J, Luquin R, Ruiz PJ, Sanchez MP (2008) Memory and exploratory impairment in mice that lack the Park-2 gene and that over-express the human FTDP-17 mutant Tau. Behav Brain Res 189:350-356.

Panda D, Goode BL, Feinstein SC, Wilson L (1995) Kinetic stabilization of microtubule dynamics at steady state by tau and microtubule-binding domains of tau. Biochemistry 34:11117-11127.

Pérez M, Lim F, Arrasate M, Avila J (2000) The FTDP-17-linked mutation R406W abolishes the interaction of phosphorylated tau with microtubules. J Neurochem 74:2583-2589.

Pérez M, Ribe E, Rubio A, Lim F, Morán MA, Ramos PG, Ferrer I, Isla MT, Avila J (2005) Characterization of a double (amyloid precursor protein-tau) transgenic: tau phosphorylation and aggregation. Neuroscience 130:339-347.

Petit-Demouliere B, Chenu F, Bourin M (2005) Forced swimming test in mice: a review of antidepressant activity. Psychopharmacology (Berl) 177:245-255.

Porsolt RD, Bertin A, Jalfre M (1977) Behavioral despair in mice: a primary screening test for antidepressants. Arch Int Pharmacodyn Ther 229:327-336.

Sahay A, Hen R (2007) Adult hippocampal neurogenesis in depression. Nat Neurosci 10:1110-1115.

Samuels BA, Hen R (2010) Neurogenesis and affective disorders. Eur $J$ Neurosci 33:1152-1159.

Snyder JS, Radik R, Wojtowicz JM, Cameron HA (2009) Anatomical gradients of adult neurogenesis and activity: young neurons in the ventral dentate gyrus are activated by water maze training. Hippocampus 19:360-370.

Swanson LW, Cowan WM (1977) An autoradiographic study of the organization of the efferent connections of the hippocampal formation in the rat. J Comp Neurol 172:49-84.

van Praag H, Christie BR, Sejnowski TJ, Gage FH (1999) Running enhances neurogenesis, learning, and long-term potentiation in mice. Proc Natl Acad Sci U S A 96:13427-13431.

Vuksic M, Del Turco D, Bas Orth C, Burbach GJ, Feng G, Müller CM, Schwarzacher SW, Deller T (2008) 3D-reconstruction and functional properties of GFP-positive and GFP-negative granule cells in the fascia dentata of the Thy1-GFP mouse. Hippocampus 18:364-375.

Winner B, Kohl Z, Gage FH (2011) Neurodegenerative disease and adult neurogenesis. Eur J Neurosci 33:1139-1151.

Wong ML, Medrano JF Real-time PCR for mRNA quantitation. Biotechniques 39:75-85.

Zhao Z, Ho L, Suh J, Qin W, Pyo H, Pompl P, Ksiezak-Reding H, Pasinetti GM (2003) A role of P301L tau mutant in anti-apoptotic gene expression, cell cycle and apoptosis. Mol Cell Neurosci 24:367-379. 